\title{
Application of Electrocoagulation for Printing Wastewater Treatment: From Laboratory to Pilot Scale
}

\author{
Nguyen Thi Thuy ${ }^{1,2,3}$, Nguyen Xuan Hoan ${ }^{1}$, Dang Van Thanh ${ }^{4}$, Pham Minh Khoa ${ }^{1}$, Nguyen Thanh Tai ${ }^{1}$, \\ Phan Quang Huy Hoang ${ }^{1}$, and Nguyen Nhat Huy ${ }^{3,5 *}$ \\ ${ }^{1}$ HCMC University of Food Industry, 140 Le Trong Tan Street, Tan Phu District, Ho Chi Minh City, Vietnam \\ ${ }^{2}$ Department of Environmental Engineering, International University, Quarter 6, Linh Trung Ward, Thu Duc District, Ho Chi \\ Minh City, Vietnam \\ ${ }^{3}$ Vietnam National University Ho Chi Minh City, Linh Trung Ward, Thu Duc District, Ho Chi Minh City, Vietnam \\ ${ }^{4}$ TNU-University of Medicine and Pharmacy, 284 Luong Ngoc Quyen road, Thai Nguyen City, Vietnam \\ ${ }_{5}^{5}$ Faculty of Natural Resources and Environment, Ho Chi Minh City University of Technology (HCMUT), 268 Ly Thuong Kiet \\ Street, District 10, Ho Chi Minh City, Vietnam
}

\begin{abstract}
This study reports for the first time the application of electrocoagulation (EC) from laboratory to pilot scales for the treatment of printing wastewater, a hazardous waste whose treatment and disposal are strictly regulated. The wastewater was taken from three real printing companies with strongly varying characteristics. The treatment process was performed in the laboratory for operational optimization and then applied in the pilot scale. The weight loss of the electrode and the generation of sludge at both scales were compared. The results show that the raw wastewater should be diluted before EC treatment if its COD is higher than about $10,000 \mathrm{mg} / \mathrm{L}$. Pilot scale removal efficiencies of COD and color were slightly lower compared to those obtained from the laboratory scale. At pilot scale, the effluent CODs removal efficiency was 81.9 88.9\% (final concentration of $448-992 \mathrm{mg} / \mathrm{L}$ ) and color removal efficiency was $95.8-98.6 \%$ (final level of 89 - 202 PtCo) which proved the feasibility of EC treatment as an effective pre-treatment method for printing wastewater as well as other high colored and hard-biodegradable wastewaters.
\end{abstract}

Keywords : Printing Wastewater, Electro-Coagulation, Laboratory Scale, Pilot Scale, Industrial Wastewater

Received : 16 July 2019, Accepted : 28 July 2020

\section{Introduction}

Printing ink is a complex, multi-component compound, composed principally of dyes, pigments, resins, binders, solvents, and optical additives. Hence, wastewater generated from the printing process is highly colored, and contaminated with organic composes because of the afore-referred compounds. Most of the components in wastewater are synthetic organic polymers with strong stability, which bring on the $\mathrm{BOD}_{5} / \mathrm{COD}$ of the wastewater generally lower than 0.4. Moreover, printing ink wastewater contains

*E-mail address: nnhuy@hcmut.edu.vn

DOI: https://doi.org/10.33961/jecst.2019.00444

This is an open-access article distributed under the terms of the Creative Commons Attribution Non-Commercial License (http://creativecommons.org/licenses/by-nc/4.0) which permits unrestricted non-commercial use, distribution, and reproduction in any medium, provided the original work is properly cited. plenty of substances inhibiting biological activity and heavy metal ions, making of difficulty to be microbial decomposed and transformed [1]. Due to the harmful effect on human health and the environment, as well as the aesthetical aspect, the printing ink wastewater cannot be directly discharged into the environment without any treatment. Practically, various methods have been used to treat this wastewater, including coagulation, adsorption, oxidation, biological treatment, electrolysis [1], electrocatalytic process [2], and electrochemical treatment [3]. Among these methods, electrocoagulation (EC) has been proposed as an effective method for treating various types of wastewater from textile, paper mill, baker's yeast, restaurant, and chemical mechanical polishing [4,5], paint manufacture wastewater [6], and lithographic wastewater [7]. However, there is very rare report on the application of this technique for printing waste- 
water [8-10]. Scaling up of EC was found for domestic greywater reuse [11] and almond industry wastewater treatment [12] but has not been conducted for printing wastewater.

To the best of our knowledge, it is the first time EC process was applied for printing wastewater treatment, from laboratory to pilot scale. Printing wastewater was collected from three printing companies, including fabric screen printing, packing printing with various branches, and paper packing printing. Firstly, experiments were performed on a laboratory scale to find the optimum condition from wastewater dilution level, input voltage, $\mathrm{pH}$, electrode distance, mixing speed, and electrolyte concentration. The treatment was then scaled up to pilot scale with both batch and continuous modes, and operated for a long duration.

\section{Methodology}

\subsection{Materials and apparatus}

Wastewater samples were collected from a fabric screen printing wastewater source in Ho Chi Minh City (Vietnam) during November 2017 to March 2018 (denoted as S1); from a packing printing wastewater source in Long An Province (Vietnam) during April to June 2018 (denoted as S2, including three subsamples, denoted as S2-1, S2-2, and S2-3). Before that, wastewater samples from another paper packing factory in An Giang Province (Vietnam) were taken from March to June 2017 (denoted as S3).

Electrodes were made by aluminum (96.61\%), with the components analyzed by X-ray fluorescence (XRF) elemental analysis as given in Table 1 .

$\mathrm{NaCl}$, acid, and base were of analytical grade (Xilong, China), purchased from Viet Hoang Long Company (Ho Chi Minh City, Vietnam). All the analyses of $\mathrm{COD}, \mathrm{BOD}_{5}$, total nitrogen, true color, and

Table 1. Components of aluminum electrodes.

\begin{tabular}{cccc}
\hline \hline Element & Weight $(\%)$ & Element & Weight $(\%)$ \\
\hline $\mathrm{Al}$ & $96.61 \pm 0.67$ & $\mathrm{Co}$ & $0.04 \pm 0.01$ \\
$\mathrm{Si}$ & $1.28 \pm 0.22$ & $\mathrm{Ni}$ & $0.10 \pm 0.01$ \\
$\mathrm{Ti}$ & $0.11 \pm 0.00$ & $\mathrm{Cu}$ & $0.16 \pm 0.00$ \\
$\mathrm{Cr}$ & 0.000 .00 & $\mathrm{Zn}$ & $0.04 \pm 0.00$ \\
$\mathrm{Mn}$ & $0.17 \pm 0.00$ & $\mathrm{Sn}$ & $0.00 \pm 0.00$ \\
$\mathrm{Fe}$ & $1.49 \pm 0.01$ & $\mathrm{Sb}$ & 0.000 .00 \\
\hline
\end{tabular}

TSS were done in Consultancy Center of O.S.H \& Environmental Technology (Ho Chi Minh City, Vietnam). $\mathrm{pH}$ was measured using PHS-550 (Taiwan). Color was measured according to $2120 \mathrm{C}$ spectrophotometric method [13] using a Photolab 6100 VIS spectrophotometer (Germany) operated at $455 \mathrm{~nm}$. TSS was analyzed followed by 2540 D [13]. COD, $\mathrm{BOD}_{5}$, and total nitrogen were analyzed followed by 5220 C (Closed Reflux, Titrimetric Method) [13], TCVN 6001-1:2008, and TCVN 6638:2000, respectively. Weight of sludge and electrode was measured using a Sartorius TE412 portable scale balance.

\subsection{Laboratory scale}

For EC treatment at the laboratory scale, wastewater was treated using a 1 -L batch cell made by polyethylene. Two similar aluminum plate electrodes with an effective area of $91 \mathrm{~cm}^{2}$ were placed vertically in the cell and connected to a DC power supply (TES 6102, Taiwan). Samples with a volume of $15 \mathrm{~mL}$ were taken from electrocoagulation cell at certain operating times for true color and COD analyses. The wastewater was first checked for dilution requirement using tap water, based on the observation of changes in the color of treated wastewater after running the treatment for $30 \mathrm{~min}$. Dilution factor (f) was the ratio between (volume of wastewater + volume of tap water) and volume of wastewater, varied from 1 to 9 . If the color of the effluent was obviously faded, the effluent was then taken to measure COD and color. To find the optimum working condition, effects of voltage $(5-40 \mathrm{~V})$ with the operation time from 0-120 min, $\mathrm{pH}(5-8)$, electrolyte $(\mathrm{NaCl})$ concentration $(0.05-0.40 \mathrm{~g} / \mathrm{L})$, and inter-electrode distance $(1-5 \mathrm{~cm})$ on COD and color removals were evaluated. The $\mathrm{pH}$ of the wastewater was adjusted by using $1 \mathrm{~N} \mathrm{NaOH}$ and $1 \mathrm{~N} \mathrm{H}_{2} \mathrm{SO}_{4}$ solutions. When the optimum operating condition was obtained, the removal efficiencies of $\mathrm{COD}, \mathrm{BOD}_{5}$, true color, and TSS were measured at this condition.

\subsection{Pilot scale}

A pilot was designed including an EC rectangular reactor $(600 \times 240 \times 300 \mathrm{~mm})$, connected to a sedimentation tank $(200 \times 200 \times 400 \mathrm{~mm})$, both made by acrylic resin. The filled volume of wastewater in the reactor was fixed at $24 \mathrm{~L}$. The number of electrodes was changed from 2 to 8 with an effective area of $720 \mathrm{~cm}^{2}$ for each aluminum electrode. The pilot was 
Table 2. Characteristics of raw wastewater from different sources.

\begin{tabular}{cccc}
\hline \hline Parameter & $\mathrm{S} 1(\mathrm{n}=10)$ & $\begin{array}{c}\mathrm{S} 2(\mathrm{n}=3, \\
\text { from S2-1, S2-2, S2-3) }\end{array}$ & $\mathrm{S} 3(\mathrm{n}=2)$ \\
\hline $\mathrm{Q}\left(\mathrm{m}^{3} / \mathrm{day}\right)$ & $2.5-3$ & - & - \\
$\mathrm{pH}$ & $6.0 \pm 0.2$ & $8.8 \pm 0.8$ & $2593 \pm 14$ \\
COD $(\mathrm{mg} / \mathrm{L})$ & $2511 \pm 510$ & $25920 \pm 5326$ & $53943 \pm 19$ \\
Color $(\mathrm{mg} / \mathrm{L})$ & $7197 \pm 1236$ & 2432 & $1125 \pm 13$ \\
BOD $(\mathrm{mg} / \mathrm{L})$ & 1162 & - & $438 \pm 16$ \\
TSS (mg/L) & 550 & 56 & - \\
Total Nitrogen $(\mathrm{mg} / \mathrm{L})$ & 51 & &
\end{tabular}

run either in batch or continuous modes. The operating condition for each type of wastewater was the corresponding optimum condition for these wastewaters from laboratory results $(30 \mathrm{~V}, 30 \mathrm{~min}, \mathrm{pH} 6-7$, electrode distance of $2 \mathrm{~cm}$, without mixing and adding of electrolyte). During the treatment, floating sludge was manually removed from the top of the tank. After treatment by EC process, the wastewater was settled for $30 \mathrm{~min}$, and samples were taken to analyze COD, color, BOD, TSS, and total nitrogen.

\section{Results and Discussion}

\subsection{Wastewater characteristics}

The characteristics of three types of wastewater are given in Table 2 and the images of wastewater can be seen in the Supplementary data (Fig. A). In general, printing wastewater is generated in a low volume but very strong in the concentration of contaminants and varies strongly depending on the sources. The reason would be the different types and concentrations of inks used in each process as well as the original printing wastewater with/without a combination of domestic wastewater or/and cleaning wastewater. In addition, the range of variation in characteristics of $\mathrm{S} 2(\mathrm{n}=3)$ was stronger than those of S1 and S3, which attributes to the change in printed products from the company that generated S2 wastewater. During this study period, their products were changed three times, resulted in three subsamples, denoted as S2-1, S2-2, and S2-3.

\subsection{Results of EC treatment at laboratory scale}

3.2.1 The need of wastewater dilution

At the beginning, the electro-coagulation treatment was designed to treat directly raw printing wastewater. This succeeded for wastewater S1 and $\mathrm{S} 3$ but did not work for wastewater S2. For raw S2 samples, applying EC treatment resulted in unstable electric currents with no visible change in color after 30 min of EC treatment. Also, very less sludge was generated and floated. Hence, different dilution factors were tested for these samples. Table 3 shows the changes in COD and color of the S2-1, S2-2, and S23 wastewater before and after treatment at different dilution factors.

For S2-1 and S2-3, applying EC treatment for samples diluted at the factors (f) of 2 and 3 still resulted in no visible change of color after $30 \mathrm{~min}$ of treatment. This is because of too high COD and color in raw wastewater (Table 2) as well as the diluted wastewater. When $\mathrm{f}$ was equal to or greater than 4 , change in color of the treated wastewater was observed.

The results from Table 3 also suggest that EC treatment seemed to work obviously for the wastewater with COD about $10000 \mathrm{mg} / \mathrm{L}$. No more dilution was required for the wastewater with $\mathrm{COD}$ lower than this recommended value. It is noted that in the case of $\mathrm{S} 2-2$, we selected the dilution factor $\mathrm{f}=3$ instead of $\mathrm{f}$ $=2$ since we desired COD in EC treated wastewater lower than $1000 \mathrm{mg} / \mathrm{L}$ to facilitate the further treatment step of the effluents. Our approach in selecting dilution differed from previous studies using EC treatment without dilution for paint manufacturing wastewater $(\mathrm{COD}=19700 \mathrm{mg} / \mathrm{L}$ [6]) and lithographic wastewater $(\mathrm{TOC}=18400 \mathrm{mg} / \mathrm{L}$ [7]). The treated wastewater from these studies still contained very high in COD (about $1182 \mathrm{mg} / \mathrm{L}$ ) and in TOC (3825 mg/L), which could be still hard for selecting the next step of treatment, especially for biological treatment. For the real industrial scale, we suggested 
Table 3. Effect of dilution factor (f) on COD and color in the effluent of S2-1, S2-2, S2-3.

\begin{tabular}{|c|c|c|c|c|c|c|c|c|c|c|c|c|}
\hline \multirow[b]{2}{*}{$\mathrm{f}$} & \multicolumn{6}{|c|}{$\mathrm{COD}(\mathrm{mg} / \mathrm{L})$} & \multicolumn{6}{|c|}{ Color (Pt-Co) } \\
\hline & $\begin{array}{l}\text { Inf- } \\
\text { S2-1 }\end{array}$ & $\begin{array}{l}\text { Eff- } \\
\text { S2-1 }\end{array}$ & $\begin{array}{l}\text { Inf- } \\
\text { S2-2 }\end{array}$ & $\begin{array}{l}\text { Eff- } \\
\text { S2-2 }\end{array}$ & $\begin{array}{l}\text { Inf- } \\
\text { S2-3 }\end{array}$ & $\begin{array}{l}\text { Eff- } \\
\text { S2-3 }\end{array}$ & $\begin{array}{l}\text { Inf- } \\
\text { S2-1 }\end{array}$ & $\begin{array}{l}\text { Eff- } \\
\text { S2-1 }\end{array}$ & $\begin{array}{l}\text { Inf- } \\
\text { S2-2 }\end{array}$ & $\begin{array}{l}\text { Eff- } \\
\text { S2-2 }\end{array}$ & $\begin{array}{l}\text { Inf- } \\
\text { S2-3 }\end{array}$ & $\begin{array}{l}\text { Eff- } \\
\text { S2-3 }\end{array}$ \\
\hline 1 & 23680 & - & 22080 & - & 32000 & - & 15908 & - & 12000 & - & 26047 & - \\
\hline 2 & - & - & 10880 & 1600 & - & - & - & - & 6512 & 211 & - & - \\
\hline 3 & NA & NA & 8480 & 864 & - & - & NA & NA & 4686 & 166 & - & - \\
\hline 4 & 6640 & 864 & 6880 & 768 & 10240 & 960 & 4549 & 136 & 3770 & 130 & 7000 & 256 \\
\hline 5 & 4720 & 832 & 5600 & 672 & 8960 & 896 & 3731 & 126 & 2441 & 94 & 4847 & 146 \\
\hline 6 & 3680 & 736 & 5120 & 608 & 6400 & 800 & 3077 & 97 & 1722 & 54 & 3650 & 107 \\
\hline 7 & 3040 & 640 & 4960 & 480 & NA & NA & 2423 & 94 & 1139 & 28 & NA & NA \\
\hline 8 & 2720 & 576 & NA & NA & NA & NA & 2096 & 64 & NA & NA & NA & NA \\
\hline 9 & 2240 & 512 & NA & NA & NA & NA & 1769 & 61 & NA & NA & NA & NA \\
\hline
\end{tabular}

Note: f: dilution factor; Inf: Influent; Eff: effluent; “_“ no measurement was performed due to no visible change in color after 30 min of EC treatment; "NA": not analyzed.

designing the system with the recycled line of treated wastewater for the dilution instead of using tap water as in this study.

\subsection{Effect of applied voltage}

The effect of applied voltage on COD and color in the effluents is plotted in Fig. 1 and the corresponding current densities are given in Table 4. Images of feed wastewater and effluents can be seen in the Supplementary data (Fig. B). It is noted that we enlarged the applied voltage to $40 \mathrm{~V}$ for the treatment of S1 and $\mathrm{S} 3$, but to $30 \mathrm{~V}$ for $\mathrm{S} 2-2$. As can be seen from Fig. $\mathrm{C}$ in the Supplementary data, the wastewater temperature increased by the increase of both voltage and treatment time. The temperature increased slowly for $\mathrm{S} 1$ with the maximum value of $41^{\circ} \mathrm{C}$ at $40 \mathrm{~V}$ and $90 \mathrm{~min}$, but significantly for S2-2, reached $95^{\circ} \mathrm{C}$ at $30 \mathrm{~V}$ and $90 \mathrm{~min}$. Hence, for safety as well as saving energy we did not operate the treatment of S22 at the voltage of $40 \mathrm{~V}$ or higher.

The increase in applied voltage (from 5 to $30 \mathrm{~V}$ ), corresponding to the current density increase (Table 4), resulted in better elimination of both COD and color in the wastewater. It is explained that current density increased led to the increase of coagulants concentration, and therefore enhancing the coagulation process. Current density increased also led to a higher number of bubbles generated, which promotes the flotation process. However, COD and color removals at $30 \mathrm{~V}$ differed insignificantly compared to that at $40 \mathrm{~V}$.
Table 4. Applied voltages and current densities in EC treatment of printing wastewater.

\begin{tabular}{cccc}
\hline \hline \multirow{2}{*}{ Voltage $(\mathrm{V})$} & \multicolumn{3}{c}{$\mathrm{i}\left(\mathrm{A} / \mathrm{m}^{2}\right)$} \\
\cline { 2 - 4 } & $\mathrm{S} 1$ & $\mathrm{~S} 2-2$ & $\mathrm{~S} 3$ \\
\hline 5 & - & - & 24 \\
10 & 16 & 99 & 36 \\
20 & 22 & 165 & 83 \\
30 & 33 & 198 & 131 \\
40 & 44 & - & 143 \\
\hline
\end{tabular}

It is further noted that for each voltage, increasing treatment time at the beginning of the period led to a significant increasing in COD and color removal. However, operating the experiment for longer time mostly unchanged or even slightly increased COD and color in the effluents. Hence, for three types of printing wastewater, the optimum voltage and time for COD removal were $30 \mathrm{~V}$ and $30 \mathrm{~min}$, which were mostly concomitant with the suitable voltage and time for color removal.

\subsubsection{Effect of $\mathrm{pH}$}

Variation in $\mathrm{pH}$ affects solution conductivity, electrodes' dissolution, forms of aluminum species, and zeta potential of colloidal particles [5]. In this study, the effect of $\mathrm{pH}$ from 5 - 9 was examined and the results are shown in Fig. 2. For S1, changing $\mathrm{pH}$ from 5 - 9 varied slightly the removal efficiency of COD 

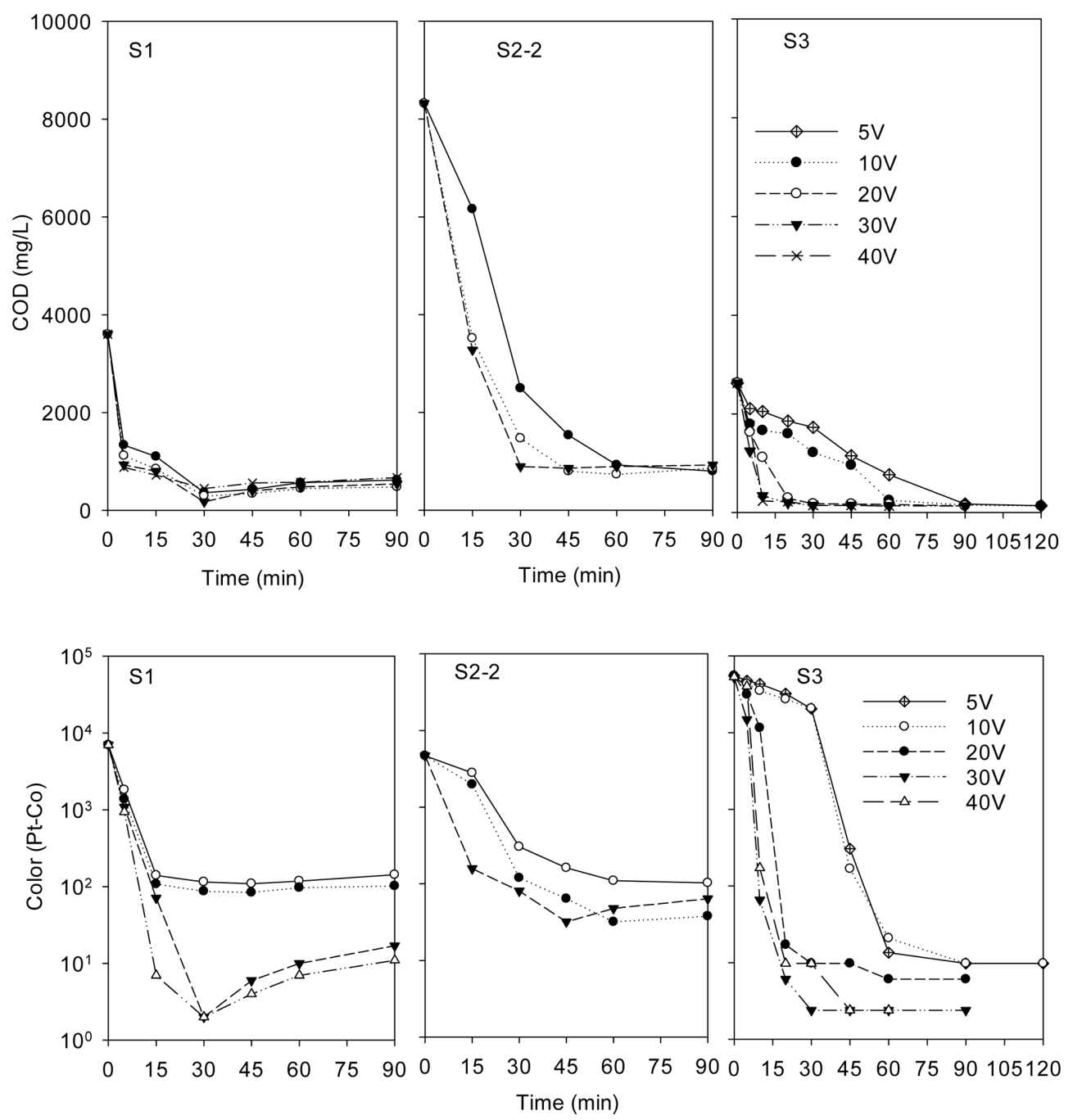

Fig. 1. Effect of applied voltage on COD and color change by time

from 84.7 to $87.8 \%$, and color from 99.4 to $99.9 \%$, suggesting the optimum $\mathrm{pH}$ of 6 . For S2-1 and S3, increasing $\mathrm{pH}$ affected strongly on COD and color removal efficiency, which firstly increased and then reduced. Maximum COD and color removal efficiency was 89.7 and $96.3 \%$, respectively, for S2-1 at $\mathrm{pH} 6$, and 89.3 and $99.9 \%$, respectively, for $\mathrm{S} 3$ at $\mathrm{pH}$ 7. For all three types of wastewater, COD removal efficiencies in this study at optimum $\mathrm{pH}$ were clearly higher compared to those provided by electrocoagulation treatment in Papadopoulos et al. [10] (72.0$85.8 \%$ ). Also, the results suggested that $\mathrm{pH} \sim 6-7$ was the optimum range for the treatment of COD and color in printing wastewater, possibly because of the dependence of the forms of aluminum species on $\mathrm{pH}$. It is well known that $\mathrm{Al}^{3+}$ ions generated from anode during electrocoagulation combine with water and hydroxyl ions to form monomeric, polymeric, amorphous and less soluble species of Al [14]. Since the solubility of aluminum hydroxide $\mathrm{Al}(\mathrm{OH})_{3}$ precipitate is minimum at $\mathrm{pH}$ of 6.0 [15], large amounts of these precipitates were formed leading to the rapid adsorption of soluble organic compounds and trapping of colloidal particles [16]. However, due to aluminum amphoteric character, $\mathrm{Al}(\mathrm{OH})_{3}$ solubility increases as the wastewater becomes either more 


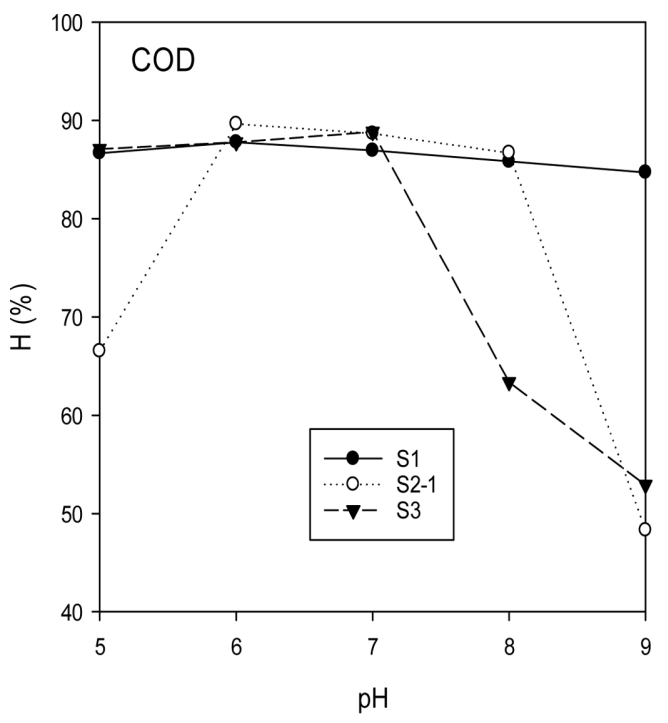

Fig. 2. COD and color removal efficiencies at different $\mathrm{pH}$.

acidic or alkaline leading to the increase of $\mathrm{Al}$ soluble forms (e.g. $\mathrm{Al}^{3+}, \mathrm{Al}(\mathrm{OH})^{2+}$ or $\left.\mathrm{Al}(\mathrm{OH})_{4}^{-}\right)$, resulted in the decreases of COD and color removal efficiency. Our approach in the adjustment of $\mathrm{pH}$ to optimum value differed from Adamovic et al. [8] where the EC treatment was directly performed at initial $\mathrm{pH}$ (11 12) for printing wastewater without the evaluation of $\mathrm{pH}$ effect. Optimum $\mathrm{pH}$ found in this study is similar to the values finding from Bensadok et al. [14] for COD and turbidity removal in cutting oil emulsions and close to the optimum $\mathrm{pH}$ (5.7) found by Valero et al. [12] for TOC removal in almond industry wastewater. However, these $\mathrm{pH}$ values differed from Suárez-Escobar et al. [7] who found optimum $\mathrm{pH}$ 8.23 for lithographic wastewater, and from Akyol [6] with optimum $\mathrm{pH}$ from 4 - 8 for paint manufacturing wastewater. Accordingly, no $\mathrm{pH}$ adjustment was required for $\mathrm{S} 1$ and $\mathrm{S} 3$ whose initial $\mathrm{pH}$ values were in the range of $6-7$, but slight acidification was needed for $\mathrm{S} 2$ with initial $\mathrm{pH}$ about 8 - 9 .

\subsubsection{Effect of electrode distance}

The distance between the two electrodes affects the electrocoagulation process as the electrostatic field depends on the distance of the electrodes [17]. Optimum electrode distance in the EC treatment varied from different studies, e.g. $0.1 \mathrm{~cm}$ [18], $0.5-1.0 \mathrm{~cm}$ [8], or $2.8 \mathrm{~cm}$ [19]. In this study, the effect of electrode distance $(1-5 \mathrm{~cm})$ on COD and color removal

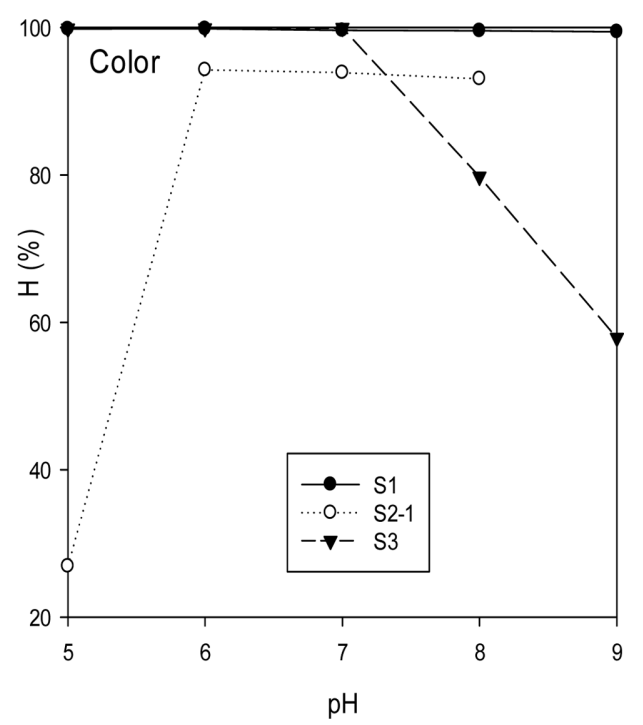

was tested. As can be seen from Fig. 3, electrode distance of 1 and $2 \mathrm{~cm}$ provided similar COD in effluents and the best color removal was found for the distance of $2 \mathrm{~cm}$. Further broadening electrodes gap $(>2 \mathrm{~cm})$ resulted in lower removal efficiencies of both COD and color which would be due to: (i) the decrease of current density at a fixed voltage, e.g. current densities were 263.74, 219.78, 142.86, and 87.91 corresponding to the distance of $1,2,3$, and $4 \mathrm{~cm}$ for S2-2. Similarly, current densities were 43.96, 32.97, 21.98, 16.48, and 10.99, corresponding to the distance of $1,2,3,4$, and $5 \mathrm{~cm}$ for $\mathrm{S} 1$. Current density reduction with the increase of electrode distance was also observed by Phan et al. [20], and further mentioned by Thella et al. [21] as a consequence of resistance increase; (ii) the decrease in the electrostatic attraction that caused a slower movement of the generated ions [17] leading to the lower removal efficiency of pollutants since Fekete et al. [22] found that the dissolved $\mathrm{Al}$ from anode being active as a coagulant for seconds only after its formation; and (iii) the diminution of mass transfer in the reactor [5].

On the other hand, a too narrow distance between two electrodes is also not recommended because metal hydroxides generated get degraded by collision with each other [23]. Thella et al. [21] also preferred not to apply too short distances to avoid short-circuiting and Sahu et al. [5] mentioned the frequent floc deposits induced by the low level of turbulence 

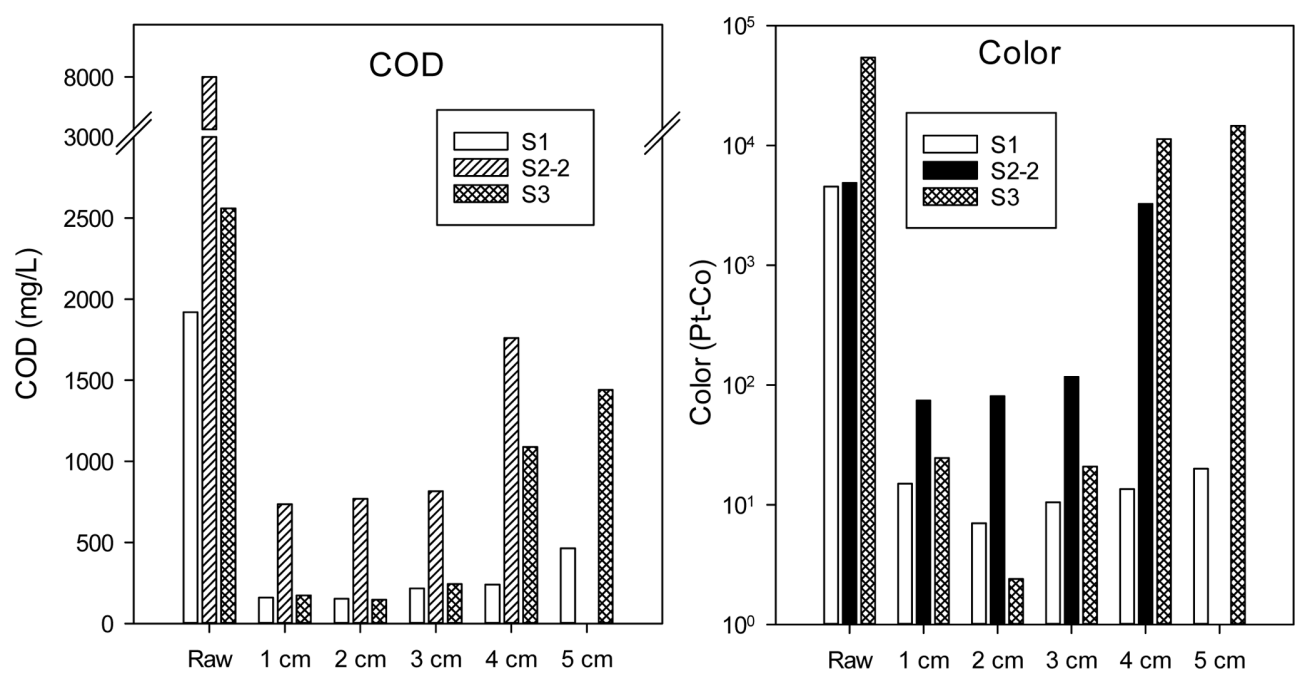

Fig. 3. Effect of electrode distance on COD and color in effluents.

between the electrodes. Hence, we selected a distance of $2 \mathrm{~cm}$ instead of $1 \mathrm{~cm}$ for the next experiments to facilitate the floating of sludge, its harvesting and the convenience in cleaning electrodes.

3.2.5 Effect of electrolyte concentration and mixing

Adding salt into the EC system can increase the conductivity of wastewater, reduce adverse effect of other anions $\left(\mathrm{HCO}_{3}{ }^{-}, \mathrm{SO}_{4}{ }^{2-}\right)$, decrease in power consumption, and provide additional disinfection [24]. In this study, electrolyte concentration in $\mathrm{S} 1$ and $\mathrm{S} 3$ was varied by adding different $\mathrm{NaCl}$ dosages, i.e. 0, 0.05, $0.1,0.2,0.3$, and $0.4 \mathrm{~g} / \mathrm{L}$. For S1, the effect of adding salt had an unclear impact on COD removal efficiency, ranged from $84-88 \%$. In a previous study, Valero et al. [12] also found the removal efficiency of TOC was unchanged (i.e. $80 \%$ ) between adding or non-adding of $\mathrm{NaCl}$. We further observed a slight decrease in COD removal efficiencies for the treatment of S3 with the increase of salt concentration added, within $91-95 \%$. Hence, the addition of salt may not be necessary for printing wastewater, possibly due to the sufficient ion existing in the raw wastewater.

Many studies apply mixing at different speeds, e.g. $200 \mathrm{rpm}$ [25], $250 \mathrm{rpm}$ [14], $450 \mathrm{rpm}$ [8], and 900 $\mathrm{rpm}$ [7] to make the reaction solution homogeneous. In this study, mixing at different speeds (i.e., 0, 100, 200, 300, and $400 \mathrm{rpm}$ ) was applied for EC treatment of S3. Interestingly, mixing led to a slight reduction in COD removal compared to no mixing, and provided no effect on color removal. The result from this study is in agreement with Phan et al. [20] who achieved the highest COD and color removal efficiency in coffee wastewater without the addition of agitation. However, it differed with the results from several studies where the optimum speed was 300 rpm for cadmium removal [26], $150 \mathrm{rpm}$ for arsenic removal [27], COD removal in poultry slaughterhouse wastewater [28], and boron removal [29]. In our study, the increase of COD in the effluent when the EC treatment applied stirring would be due to the breaking of flocs, and some floating sludge returning back to the solution under stirring. It is further noted that bubbles generated at two electrodes already assisted the mixing in the solution. Since the effect of stirring speeds has not been tested for wastewater S1 and S2, further investigation is needed for this factor with a broader type of printing wastewater. For the next experiments, we decided not to apply stirring in the electrocoagulation reactor.

\subsection{Results of EC treatment at pilot scale}

The results from laboratory experiments provided us the feasibility of EC for the actual treatment of printing wastewater. Optimum conditions in terms of wastewater dilution, applied voltage, $\mathrm{pH}$, electrode distance, mixing, and electrolyte concentration were finalized for each type of wastewater and were applied for pilot scale to treat S1 and S2. 


\subsubsection{Effect of the number of electrodes}

According to the result from laboratory scale, ratio between electrodes area/wastewater volume $(\mathrm{S} / \mathrm{V})$ was $2 \times 91\left(\mathrm{~cm}^{2}\right) / 1(\mathrm{~L})=18.2\left(\mathrm{~m}^{2} / \mathrm{m}^{3}\right)$. For the pilot scale, we tended to keep the value close to this ratio, by applying 6 electrodes with monopolar arrangement (Fig. D in the Supplementary data), resulted in the ratio of $\left[(6 \times 720)(\mathrm{cm})^{2} / 240(\mathrm{~L})=18.0\left(\mathrm{~m}^{2} / \mathrm{m}^{3}\right)\right.$. This ratio was a few higher than the value selected by Khaled et al. [26] (i.e. $13.6 \mathrm{~m}^{2} / \mathrm{m}^{3}$ ). In addition, the effect of the number of electrodes from 2 to 8 on COD and color removal was investigated for $\mathrm{S} 1$. The current intensity was also kept at optimum condition found from laboratory scale, i.e. $33 \mathrm{~A} / \mathrm{m}^{2}$ for individual unit.

As can be seen from Fig. 4, the increase in the number of electrode improved the removal of both COD and color because of the enlarging active surface [26]. This trend was similar as the findings from Akbal and Camc1 [30] for electrode number increas-

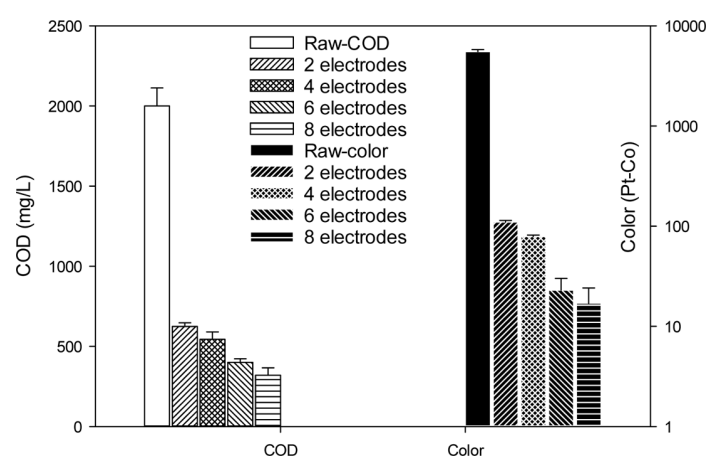

Fig. 4. Effect of number of electrodes on the COD and color effluent $(\mathrm{S} 1)(\mathrm{n}=3)$. ing from 2 to 6 in the removal of $\mathrm{Cu}, \mathrm{Cr}$, and $\mathrm{Ni}$, and from Ahmadian et al. [31] with electrode number from 4 to 8 to treat slaughterhouse wastewater. In term of $\mathrm{S} / \mathrm{V}$ ratio, our results reinforced that increase in $\mathrm{S} / \mathrm{V}$ ratio by increase of electrode number led to the increase in removal efficiency, which is consistent with the trend found by Khaled et al. [26] where much better removal efficiency of cadmium was achieved with larger $\mathrm{S} / \mathrm{V}$ ratio. It is noted that this study changed the total electrical current applied for the system to keep the current density of each unit at $33 \mathrm{~A} / \mathrm{m}^{2}$ as the optimum value found from the laboratory experiment. Hence, when the number of electrode increased, the total current required increased, resulted in the increase in power consumption. Since the improvement of removal efficiency was more obvious when the number of electrodes increased from 4 to 6 (i.e. $7.2 \%$ for COD and $1.0 \%$ for color) compared from 6 to 8 (i.e. $4.0 \%$ for COD and $0.1 \%$ for color), 6 electrodes were selected as appropriate number.

3.3.2 Comparison between pilot scale and laboratory scale in batch operation

It is obvious that performing the treatment in the laboratory scale where most of the conditions are well controlled will result in better removal efficiency as compared to the treatment on the pilot scale. As demonstrated in Fig. 5, removal efficiencies at the pilot scale were $81.9 \%$ COD and $98.6 \%$ color for S1 and $88.9 \%$ COD and $95.8 \%$ color for S2-2. These efficiencies were lower than those achieved from laboratory scale but the difference in efficiency was small, i.e. $2.6 \%$ for COD and $0.9 \%$ for color of $\mathrm{S} 1$, and $1.4 \%$ for $\mathrm{COD}$ and $1.5 \%$ for color of $\mathrm{S} 2-2$.

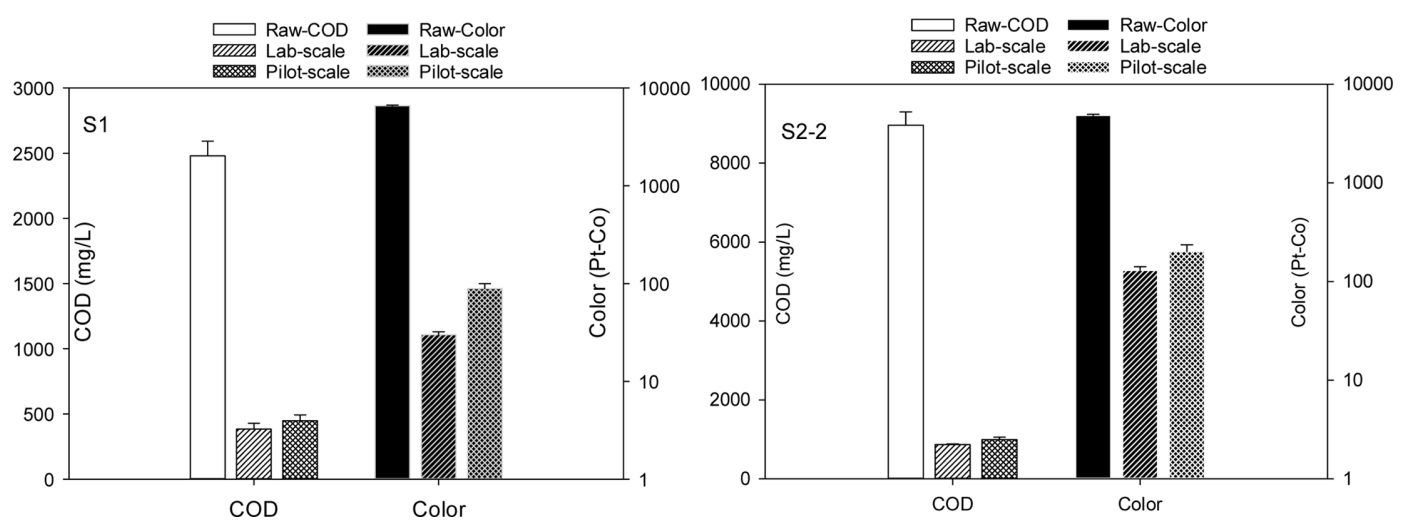

Fig. 5. Comparison between laboratory scale and pilot scale on COD and color removal from $\mathrm{S} 1$ and $\mathrm{S} 2-2(\mathrm{n}=3)$. 


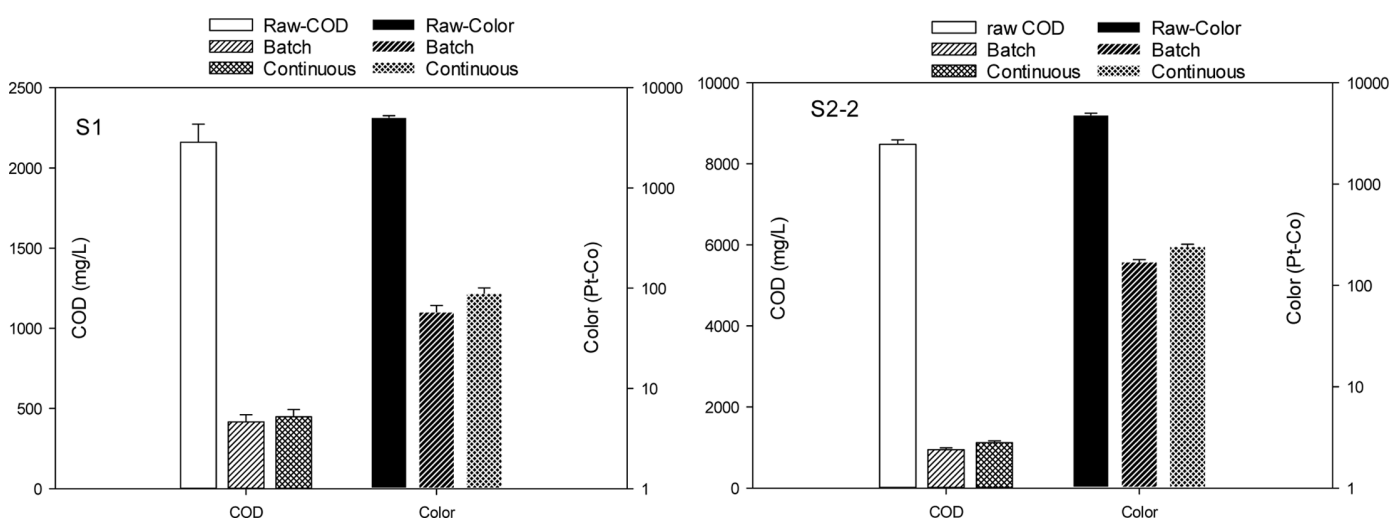

Fig. 6. Effect of operational modes on COD and Color in effluents of S1 and S2-2 ( $n=3)$.

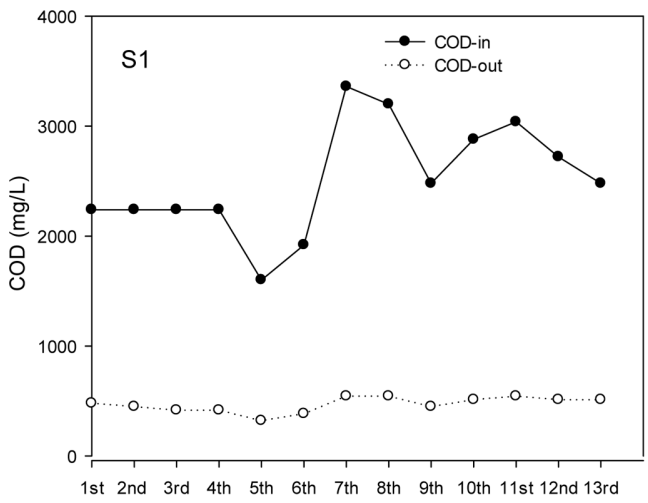

Day

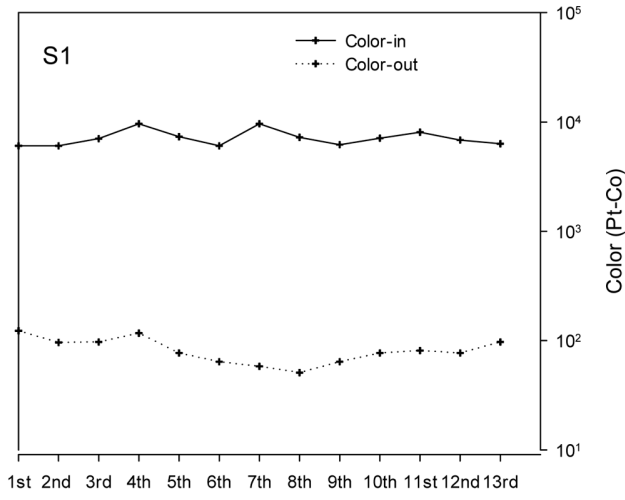

Day

Fig. 7. COD and color in raw and treated wastewater for long EC treatment operation.

The images of feed wastewater and effluents after lab and pilot-scale treatment can be found in Fig. E in the Supplementary data.

3.3.3 Comparison between batch and continuous operation

Selection of batch or continuous operation modes depends on the discharging regime of the source as well as the volume of the printing wastewater. While the batch mode is suitable for the wastewater discharged intermittently in low volume, the continuous mode is preferred for the case of wastewater discharged continuously with a larger volume. In this study, we examined the performance of both operation modes using S1 and S2-2 samples, and the results are given in Fig. 6 . Obviously, compared to continue mode operation, batch mode provided a slightly better COD and color removal efficiency. The difference in efficiency between batch and continue modes were $1.5 \%$ COD and $0.62 \%$ color for S 1 , and $2.07 \%$ COD and $1.52 \%$ color for $\mathrm{S} 2$.

\subsubsection{Operation for long duration}

To test the stability of the wastewater treatment system in the pilot scale, experiments were conducted using continuous mode with $8 \mathrm{~h}$ /day for 13 days using in-situ S1 wastewater. As can be seen from Fig. 7, though COD in the raw wastewater varied strongly during 13 days, from 1600 to $3360 \mathrm{mg}$ / $\mathrm{L}, \mathrm{COD}$ in the effluent was quite stable in the range of 302 - $544 \mathrm{mg} / \mathrm{L}$. Similarly, the color in raw wastewater was from 6060 to $9619 \mathrm{Pt}-\mathrm{Co}$, resulted in color of 51 - 123 Pt-Co after EC treatment. This relatively stable outlet concentration of COD and color despite the high variation in the inlet suggests $\mathrm{EC}$ as a very 
Table 5. Summary of effluents' characteristics after EC treatment by pilot scale.

\begin{tabular}{cccc}
\hline \hline Parameter & S1 & S2-3 & QCVN 40:2011/BTNMT, column B \\
\hline $\mathrm{pH}$ & $6.5-7.5$ & $7.5-8.5$ & $5.5-9$ \\
COD $(\mathrm{mg} / \mathrm{L})$ & 448 & 992 & 150 \\
Color $(\mathrm{mg} / \mathrm{L})$ & 89 & 202 & 150 \\
TSS $(\mathrm{mg} / \mathrm{L})$ & 40 & 36 & 100 \\
Total N (mg/L) & 7 & 40,6 & 40 \\
\hline
\end{tabular}

Table 6. Weight loss of electrodes $(\mathrm{S} 1)(\mathrm{n}=2)$.

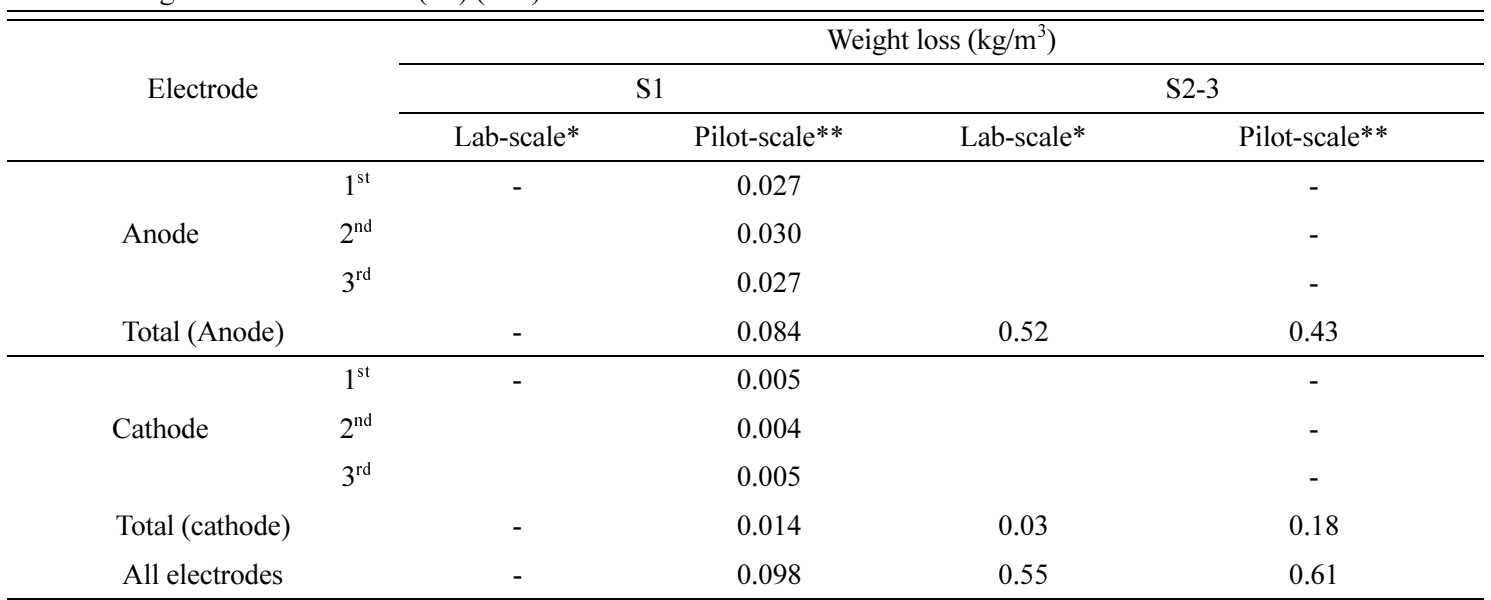

$*$ For lab scale, number of electrode was $2 ; * *$ pilot scale, number of electrode was 6 .

potential technology for the treatment of printing wastewater in practical application.

\subsubsection{Effluent characteristics}

Table 5 shows the characteristics of treated wastewater (S1, S2-3) at the pilot scale and the standard for industrial wastewater discharging. Obviously, the values of all parameters were significantly reduced. Though $\mathrm{pH}$, TSS, total nitrogen met the standard, COD and color (for S2-3) were still higher than the allowable values. The remaining COD, color, and BOD in treated wastewater possibly existed in the dissolved forms which could not be effectively removed by electro-coagulation. Similarly, previous studies also using electrocoagulation for paint manufacturing wastewater [6] and lithographic wastewater [7], printing ink wastewater [10], resulted in the treated wastewater still high in COD $(1182 \mathrm{mg} / \mathrm{L})$, TOC $(3825 \mathrm{mg} / \mathrm{L})$, and COD ( $\geq 2000 \mathrm{mg} / \mathrm{L})$, respectively. Hence, the electrocoagulation treatment is suitable as an effective pre-treatment for printing wastewater, and an advanced treatment process is needed to remove the remaining contaminants.

\subsection{Electrode weight loss and sludge generation from EC treatment}

The weight loss of anode and cathode electrodes was measured for both laboratory and pilot scale from the treatment for S1 wastewater after running the operation for $30 \mathrm{~min}$. As can be seen from Table 6 , in pilot scale the weight loss of each either anode or cathode electrodes differed slightly from the others. Total weight loss from both anode and cathode electrodes was $0.098 \mathrm{~kg} / \mathrm{m}^{3}$ which was a few lower than the weight loss given by Valero et al. [12] for almond industry wastewater in pilot scale. For S2-3, weight loss of all electrodes in the pilot scale was slightly higher compared to that in the lab scale. It is further noted that the treatment of S2-3 consumed a higher amount of aluminum than that of S1 due to the higher electrical current applied for S2-3 (Table 4).

Sludge generated was collected for five minutes and dried at $105^{\circ} \mathrm{C}$ before weight measurement. The dried sludge generated at the pilot scale for $\mathrm{S} 1$ was $6.55 \mathrm{~kg} / \mathrm{m}^{3}$ while this value was higher (i.e. $8.23 \mathrm{~kg}$ / $\mathrm{m}^{3}$ ) at the laboratory scale. These both values are in the range found by Akyol [6] in paint wastewater 
treatment at the laboratory scale (approximately 5 $16 \mathrm{~kg} / \mathrm{m}^{3}$ ). For S2-2 treatment, the amount of dried sludge collected for the pilot scale was $157.95 \mathrm{~kg} / \mathrm{m}^{3}$ which is significantly higher than those from $\mathrm{S} 1$ treatment because of significantly higher COD in S22 feed water (Table 2 and Table 3 ).

\section{Conclusions}

For the first time, electrocoagulation (EC) was applied to treat real printing wastewater both in laboratory and pilot scales, proving the feasibility of this technique as an effective pre-treatment method for these strong COD and high color wastewaters to decrease the COD to less than $1000 \mathrm{mg} / \mathrm{L}$ and facilitate the further treatment step of the effluents. The selection of this technology for printing wastewater was based on the fact that this wastewater is generally generated in small volumes but with high COD concentration and strong color. EC treatment was firstly run in a laboratory scale to find the optimum operating condition for each type of wastewater. While the optimum condition of applied voltage $(30 \mathrm{~V}), \mathrm{pH}(6-7)$, electrode distance $(2 \mathrm{~cm})$ was similar for three types of printing wastewater, their optimum current density was significantly differed, from 33 to $198 \mathrm{~A} / \mathrm{m}^{2}$. The results of this study also recommended conducting electrocoagulation treatment without mixing and adding electrolyte. EC treatment at the pilot scale was then applied at both batch and continuous operations, and for a long duration. Removal efficiencies for the pilot scale were 81.9 $88.9 \%$ for COD and 95.8 - $98.6 \%$ for color which were slightly lower compared to laboratory scale $(87.8$ - $89.7 \%$ for COD and $96.3-99.9 \%$ for color). The weight loss of the electrode and the sludge generated were also considered for both lab and pilot scales. Running the system for 13 days showed stable concentrations of COD and color in the effluent though these parameters in feed wastewater highly varied.

\section{Acknowledgement}

This work has been sponsored and funded by Ho Chi Minh City University of Food Industry under Contract No.146/HĐ-DCT. We thank the students Huynh Minh Duc and Nguyen Thi Hong Phan for their kindly help in sampling and analysis.

\section{Supporting Information}

Supporting Information is available at https:// doi.org/10.33961/jecst.2019.00444

\section{References}

[1] L. Ding, Y. Chen and J. Fan, Journal of Environmental Chemistry and Ecotoxicology, 2011, 3(10), 272-276.

[2] C.-H. Tung, S.-Y. Shen, J.-H. Chang, Y.-M. Hsu and Y.C. Lai, Sep. Purif. Technol., 2013, 117, 131-136.

[3] Z. Liu, Y. Chen, S. Hu, J. Qiu, Y. Meng and L. Li, Chemical Engineering Transactions, 2016, 55, 85-90.

[4] V. Kuokkanen, T. Kuokkanen, J. Ramo and U. Lassi, Green and Sustainable Chemistry, 2013, 3(2), 89-121.

[5] O. Sahu, B. Mazumdar and P. K. Chaudhari, Environmental Science and Pollution Research, 2014, 21(4), 2397-2413.

[6] A. Akyol, Desalination, 2012, 285, 91-99.

[7] A. Suárez-Escobar, A. Pataquiva-Mateus and A. LópezVasquez, Catal. Today, 2016, 266, 120-125.

[8] S. Adamovic, M. Prica, B. Dalmacija, S. Rapajic, D. Novakovic, Z. Pavlovic and S. Maletic, Arabian Journal of Chemistry, 2016, 9(1), 152-162.

[9] N. T. Thuy, C. T. Bao, D. X. Son, U. D. Bao, D. V. Thanh and N. N. Huy, Vietnam Journal of Science and Technology, 2017, 55(4C), 192.

[10] K. P. Papadopoulos, R. Argyriou, C. N. Economou, N. Charalampous, S. Dailianis, T. I. Tatoulis, A. G. Tekerlekopoulou and D. V. Vayenas, J. Environ. Manage., 2019, 237, 442-448.

[11] C.-J. Lin, S.-L. Lo, C.-Y. Kuo and C.-H. Wu, J. Environ. Eng., 2005, 131(3), 491-495.

[12] D. Valero, J. M. Ortiz, V. García, E. Expósito, V. Montiel and A. Aldaz, Chemosphere, 2011, 84(9), 12901295.

[13] APHA-AWWA-WEF, Standard methods for the examination of water and wastewater (21st ed), Washington, D. C, 2005.

[14] K. Bensadok, S. Benammar, F. Lapicque and G. Nezzal, Journal of Hazardous Materials, 2008, 152(1), 423-430.

[15] Metcalf and Eddy, Wastewater engineering : treatment and reuse, McGraw-Hill, Boston, 2003.

[16] M. Kobya, H. Hiz, E. Senturk, C. Aydiner and E. Demirbas, Desalination, 2006, 190(1-3), 201-211.

[17] V. Khandegar and A. K. Saroha, J. Environ. Manage., 2013, 128, 949-963.

[18] S. T. McBeath, M. Mohseni and D. P. Wilkinson, Environ. Technol., 2020, 41(5), 577-585.

[19] E. Mohora, S. Rončević, B. Dalmacija, J. Agbaba, M. Watson, E. Karlović and M. Dalmacija, J. Hazard. Mater, 2012, 235, 257-264.

[20] H. Q. H. Phan, N. X. Hoan, N. N. Huy, N. D. D. Duc, N. T. N. Anh, N. T. Que and N. T. Thuy, Journal of Environment and Sustainability, 2019, 3(3), 127-212. 
[21] K. Thella, B. Verma, V. C. Srivastava and K. K. Srivastava, Journal of Environmental Science and Health, Part A, 2008, 43(5), 554-562.

[22] É. Fekete, B. Lengyel, T. Cserfalvi and T. Pajkossy, $J$. Solid State Electrochem., 2016, 20(11), 3107-3114.

[23] E. Bazrafshan, L. Mohammadi, A. Ansari-Moghaddam and A. H. Mahvi, J Environ Health Sci Eng, 2015, 13(1), 74 .

[24] G. Chen, Sep. Purif. Technol., 2004, 38(1), 11-41.

[25] Q. H. Nguyen, T. Watari, T. Yamaguchi, Y. Takimoto, K. Niihara, J. P. Wiff and T. Nakayama, International Journal of Electrochemical Science, 2020, 15, 39-51.

[26] B. Khaled, B. Wided, H. Béchir, E. Elimame, L. Mouna and T. Zied, Arabian Journal of Chemistry, 2019, 12(8), 1848-1859.

[27] B. Z. Can, R. Boncukcuoglu, A. E. Yilmaz and B. A. Fil, J Environ Health Sci Eng, 2014, 12(1), 95.

[28] S. Bayar, Y. Ş. Yıldız, A. E. Yılmaz and Ş. İrdemez, Desalination, 2011, 280(1-3), 103-107.

[29] A. E. Yılmaz, R. Boncukcuoğlu, M. M. Kocaker¥m and E. Kocadağistan, Desalination, 2008, 230(1-3), 288-297.

[30] F. Akbal and S. Camc1, Chemical Engineering \& Technology, 2010, 33(10), 1655-1664.

[31] M. Ahmadian, N. Yousefi, S. W. Van Ginkel, M. R. Zare, S. Rahimi and A. Fatehizadeh, Water Sci. Technol., 2012, 66(4), 754-760. 